\title{
Optimal Priority Structure, Capital Structure, and Investment
}

\author{
Dirk Hackbarth \\ David C. Mauer \\ University of Illinois \\ University of Texas, Dallas
}

FARFE Conference

MIT, October 2009 


\section{Motivation of the Model}

- Since Modigliani and Miller (1958) corporate finance researchers have been interested in the issue of how financial structure influences and in turn is influenced by investment policy.

- A vast literature follows Jensen and Meckling (1976) and Myers (1977).

- Yet, it is still unclear...

- whether the loss in firm value attributable to these suboptimal investment incentives constitutes a significant component of the agency costs of debt?

- in which ways these agency costs matter for observed corporate outcomes?

- how financial contracts have evolved to control conflicts of interest between stockholders and bondholders?

- Objective of this paper:

- Study how capital structure and priority structure interact with equity-value- or firm-value-maximizing investment in a dynamic model of constrained firms (equityfinanced investment) and unconstrained firms (debt-equity financed investment). 


\section{Motivation of the Model}

- A novel feature is the recognition that the existing capital structure influences future investment decisions through two channels.

- First, there is the standard stockholder-bondholder conflict attributable to the existing capital structure over the timing of the investment decision.

- Second, there is the largely ignored role played by how future investment is financed, which is the key focus of our analysis.

- Recognizing that future investment may be financed with a combination of equity and debt has important consequences for the existing capital structure, the nature of the investment conflict, and ultimately for the dynamic evolution of financial contracts.

- One interesting and novel feature of this feedback from future to current financing decisions and vice versa is the critical and heretofore unrecognized role that priority structure plays in resolving stockholder-bondholder conflicts. 


\section{Key Dimensions of the Model}

- Firm composed of assets in place (current debt capacity) and an investment or growth option to expand (future debt capacity).

- Investment is irreversible and investment benefits are uncertain.

- Investment timing is endogenously determined by management to maximize either the market value of equity (second-best policy) or the market value of debt and equity (first-best policy).

- Firm makes initial choice of debt/equity mix by trading off investment and tax benefits against agency and bankruptcy costs.

- Constrained firm chooses an initially optimal debt/equity mix.

- Unconstrained firm chooses twice: it has multiple classes of debt.

- Equal priority (pari passu), me-first for initial debt, me-first for additional debt issued to finance the growth option, and an endogenous (optimal) choice of priority

- Endogenous (i.e., equity-value maximizing) bankruptcy decision. 


\section{Time Line of the Model}

- Firm with earnings $X_{0}$ selects optimal debt coupon $C_{0}$ at time $t=0$.

- After $t=0$, firm's earnings $X_{t}$ follow geometric Brownian motion.

- If constrained, then no further debt issues: either invest or default.

- When investing, earnings increase from $X_{t}$ to $\Pi X_{t}$, where $\Pi>1$.

- If unconstrained, then issue debt coupon $C_{s}$ and choose priority.

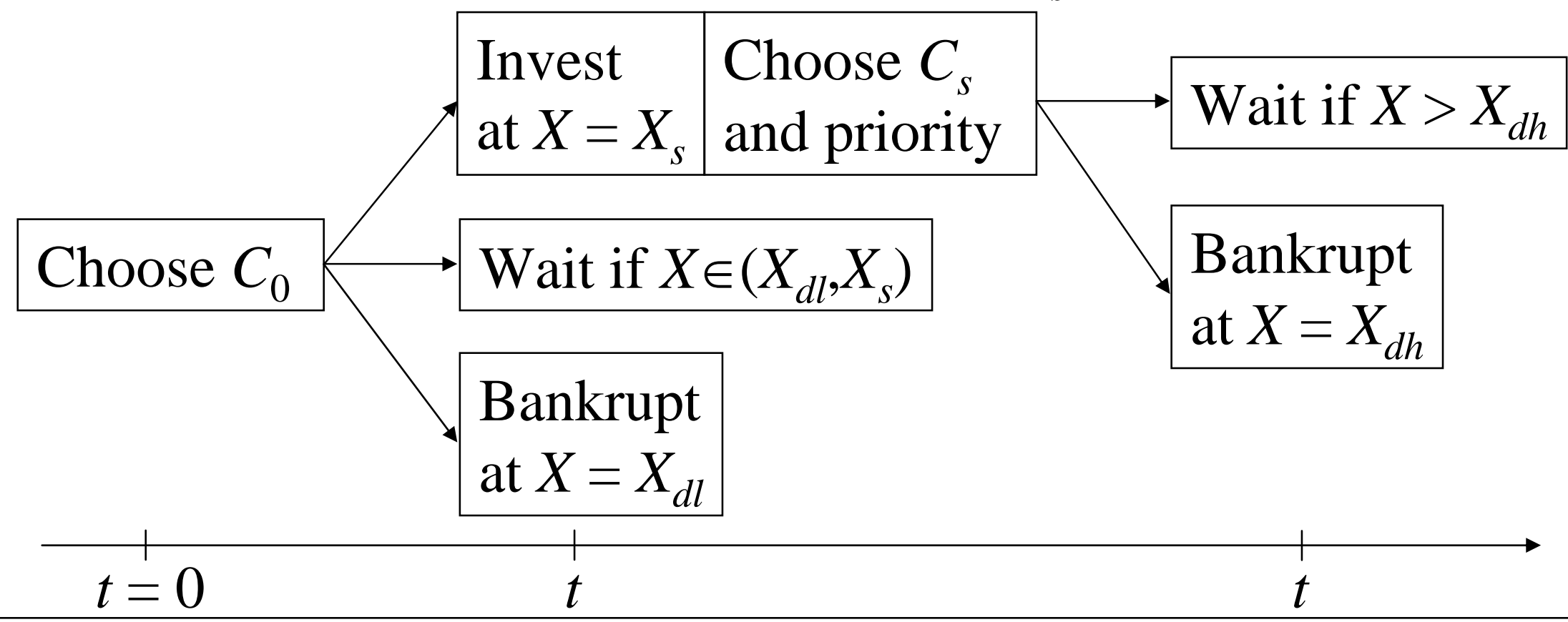




\section{Key Findings of the Model}

- In our dynamic model, firm may underinvest or overinvest in the growth option depending on (among other firm characteristics) its

- capital structure,

- priority structure,

- constraint status.

- A novel role for priority structure as optimal financial contract.

- A lower rated firm tends to spread priority across debt classes.

- An investment-based explanation of the debt conservatism puzzle.

- A non-monotonic relation between credit spreads and agency costs.

- An inverse relation between leverage and Tobin's $Q$ w/o agency.

- An alternative proxy for agency conflicts over investment policy. 


\section{Types of Debt Priority Structure}

- The ex-post "status in bankruptcy" is relevant to ex-ante valuation.

- If investment is debt-financed, it is relevant to investment timing.

- A natural base case is equal priority:

- Coupon weights $\beta_{0}=C_{0} / C$ and $\beta_{s}=C_{s} / C$ where $C \equiv C_{0}+C_{s}$ apportion liquidation value function, $L(\cdot)$, among the debt classes.

- Under pari passu priority, debt classes receive $\beta_{0} L(\cdot)$ and $\left(1-\beta_{0}\right) L(\cdot)$ in bankruptcy.

- Of course, there are alternatives to the base case of equal priority:

- Me-first covenant for initial debt (most common in practice)

- Me-first covenant for additional debt (e.g. arises under DIP financing)

- Endogenous (optimal) priority structure (theoretically desirable outcome)

- The strength afforded by me-first covenants is given by $\theta \in[0,1]$ :

- If debt $i \in\{0, s\}$ is senior, then it claims in default: $R_{i}(\cdot)=\min \left\{L(\cdot), \theta C_{i} / r\right\}$

- If debt $j \in\{0, s\}$ is junior, then it claims: $L(\cdot)-R_{i}(\cdot)=\max \left\{L(\cdot)-\theta C_{i} / r, 0\right\}$ 


\section{Optimal Debt Priority Structure}

- Priority structure plays a key role in optimal financial contracts.

- What is the intuition behind this result?

- Interestingly, capital structure by itself can completely eliminate underinvestment incentives by relaxing all-equity constraint (i.e., partial debt financing of investment).

- Fix $C_{0}$ and raise $C_{s}$ until first-best investment obtains under second-best optimizer.

- Optimize $C_{0}$ and $C_{s}$ s.t. first-best investment obtains under second-best optimizer.

- However, this "controlled” financial contracting solution is suboptimal since it does not fully exploit the incremental debt capacity of the firm's growth option.

- Unconstrained firm under equal priority of the two debt issues optimally chooses a higher $C_{s}$ than needed for first-best investment.

- Equityholders' investment incentives shift from underinvestment to overinvestment. 


\section{Optimal Debt Priority Structure}

- Alternative covenants cannot resolve these investment distortions:

- Back to underinvestment if initial debt has me-first covenant.

- Back to overinvestment if additional debt has me-first covenant.

- When debt priority is endogenized along with capital structure, there is an interior optimal priority structure which virtually eliminates both undeinvestment and overinvestment incentives.

- Allocates enough priority to initial debt to discourage equity's dilution incentives.

- Preserves priority for additional debt to boost proceeds from additional debt issue.

- Priority structure plays a key role in optimal financial contracts.

- Jointly optimal capital and priority structure utilize incremental debt capacity fully.

- Jointly optimal capital and priority structure solves agency issues over investment.

- As a result, (debt) priority structure is a critical and heretofore unrecognized financial contracting device that helps to resolve stockholder-bondholder conflicts over investment policy. 


\section{Spreading Priority Across Debts}

- Priority structure also plays a key role for extremely levered firms.

- E.g., leveraged buyout, leveraged recapitalization, pro-active leverage increases.

- Optimally levered firms allocate more priority to the initial debt.

- Overly levered firms place more priority on subsequent debt issues.

- High initial leverage reduces debt capacity and curbs investment.

- Firms respond by allocating more priority to future debt issues.

- Highly levered firms will spread priority more across debt classes.

- Initially high debt can result from a series of negative shocks rather than a choice.

- As the initial debt increases, the implied credit rating deteriorates.

- Experiments with extreme leverage are a gauge for credit ratings and priority.

- Lower rated firms will spread priority more across debt classes.

- Consistent with empirical evidence of Rauh and Sufi (2009) who find that firms spread priority among multiple tiers of debt as their credit quality weakens. 


\section{Conservative Debt Policy Puzzle}

- Empirical leverage is too low to be explained by trade-off models.

- 31\% (1965-2000, COMPUSTAT firms) compared to 65\%-85\% (Leland (1994)).

- More debt can increase firm value substantially (Graham (2000)).

- If firms can refinance in the future they opt for less debt today to decrease chances of distress (Goldstein, Ju, and Leland (2001)).

- Is only true for one-sided upward restructuring. Fischer, Heinkel and Zechner (1989) find similarly high leverage ratios with two-sided "return point" policies.

- Our model's answer to the debt conservatism puzzle is 25-35\%:

- Debt conservatism in our model arises because the debt capacity of future growth options has a downward influence on the current level of debt.

- Thus, the interaction between financing and investment decisions in a dynamic setting may give the appearance of debt conservatism, but firms do optimize.

- Importantly, we find this result even when there is no agency conflict over the timing of the investment decision (i.e., for firm-value-maximizing investment).

- First-best optimizers prefer earlier investment benefits over additional tax benefits. 


\section{Leverage and Tobin's $Q$}

- An inverse relation between market leverage and Tobin's $Q$ may not be evidence of agency costs of debt.

- Our analysis shows that there is an inverse relation between market leverage and the market-to-book ratio with or without agency costs of debt.

- Incremental debt capacity of growth options may not be negative.

- We find a positive relation between book leverage and Tobin's $Q$ even when there are agency conflicts over the exercise of future growth options.

- The relation between leverage and growth opportunities depends on whether empiricists use a book or a market leverage measure.

- Indeed, Fama and French (2002), Chen and Zhao (2006), and Frank and Goyal (2009) find book leverage is positively related to market-to-book.

- Chen and Zhao (2006) further find that credit spreads decrease in the market-to-book ratio, which helps to explain why book leverage and Tobin's $Q$ can be positively related in our model. 


\section{Credit Spreads and Leverage}

- Importantly, only when leverage is exogenous do we find that the second-best credit spread exceeds the first-best credit spread.

- Although the agency conflict dampens the firm's appetite for leverage in the second-best outcome by raising the cost of debt financing (i.e., the credit spread), the resulting lower optimal leverage choice in comparison to the case without the agency conflict results in a strictly lower equilibrium credit spread.

- Intuitively, first-best optimizers have more debt capacity at their disposal.

- We believe that this result has not been discussed in the literature, even though it is clearly present in many other dynamic models (e.g., Childs, Mauer, and Ott (2005)).

- In spite of credit spreads being used in empirical tests, they are not reliable measures of stockholder-bondholder agency costs, if debt policy is clearly endogenous or, at least, not clearly exogenous. 


\section{Proxy for Agency Conflicts}

- When debt policy is endogenous, this is a rather formidable task.

- Our model's analysis illustrates that credit spreads are unreliable indicators of agency costs of debt.

- Our model's analysis illustrates that empirical relations between either book leverage or market leverage and measures of growth opportunities are also unreliable indicators for the existence of agency conflicts arising from growth opportunities.

- Our model's analysis suggests that a potentially fruitful avenue for empirically testing the impact of agency conflicts on investment policy is to employ duration analysis, which focuses on the time elapsed between intermittent investments (see Appendix A).

- Disclaimer: While this is an alternative and under-explored proxy, it is clearly not free from problems plaguing existing proxies for agency conflicts over investment. 


\section{Conclusions}

- Optimal capital and priority structure decisions interacting with equity-value- or firm-value-maximizing investment decisions in a dynamic model of constrained firms and unconstrained firms.

- A few of our model's key findings are as follows:

- Priority structure plays a critical role in mitigating stockholder-bondholder conflict.

- Jointly optimal capital and priority structure can solve agency problem over investment.

- Lower rated firms will optimally spread priority more across debt classes.

- A rational explanation for the so-called conservative debt policy puzzle.

- Leverage- $Q$ is unreliable indicator of agency conflicts over investment.

- We currently study additional/related research issues:

- What cross-sectional variations does the model predict for e.g.

- optimal priority for refinancing without investing (a benchmark)?

- optimal priority as a function of investment benefits (or costs)?

- optimal priority as a function of more or less tangible assets?

- How can we extend this class of Leland (1994) models? 